\title{
Mediastinal Germ Cell Tumor T1a TNM
}

Finding

National Cancer Institute

\section{Source}

National Cancer Institute. Mediastinal Germ Cell Tumor T1a TNM Finding. NCI

Thesaurus. Code C146834.

Mediastinal germ cell tumor confined to the org an of orig in (thymus and mediastinal fat) and measuring $5 \mathrm{~cm}$ or less. (WHO Classification of T umors of the Lung, Pleura, Thymus and Heart, 2015) 